\title{
Non-adherence to anti-tuberculosis treatment, reasons and associated factors among TB patients attending at Gondar town health centers, Northwest Ethiopia
}

\author{
Habtamu Sewunet Mekonnen ${ }^{*}$ and Abere Woretaw Azagew
}

\begin{abstract}
Objective: The aim of this study was to assess the prevalence of non-adherence to anti-tuberculosis treatment, reasons and associated factors among TB patients attending at Gondar town health centers.

Result: A total of 314 participants were included with the response rate of $97.5 \%$. The mean age of participants was 35.94 (SD \pm 13.83 ) years. The overall rate of non-adherence to anti-TB treatment was $21.2 \%(95 \% \mathrm{Cl} 17.2,26.1)$. Continuation phase of treatment $(\mathrm{AOR}=2.27,95 \% \mathrm{Cl}(1.54,5.94))$, presence of more than one co-morbidity ( $\mathrm{AOR}=6.22$; $95 \% \mathrm{Cl}(2.21,17.48)$ ), poor knowledge about TB and anti-TB therapy ( $\mathrm{AOR}=4.11 ; 95 \% \mathrm{Cl} 1.57,10.75)$, poor patientprovider relationship (AOR $=4.60,95 \% \mathrm{Cl} 1.63,12.97)$, and alcohol intake $(A O R=5.03 ; 95 \% \mathrm{Cl} 1.54,16.40)$ were significantly associated with non-adherence. Forgetting 40 (23.1\%), Being busy with other work 35 (20.2\%), and being out of home/town 24 (13.9\%) were the major reasons of participants for interruption of taking anti-TB medications.
\end{abstract}

Keywords: Prevalence, Reasons, Non-adherence, Tuberculosis treatment, Ethiopia

\section{Introduction}

Tuberculosis (TB) is airborne infectious disease caused by Mycobacterium tuberculosis [1]. It is one of the ten top causes of death worldwide from curable infectious diseases. Globally there were estimated 10.4 million new TB cases, and 600,000 new cases with resistance to rifampicin, 490,000 had multidrug-resistant tuberculosis (MDR-TB) cases and 1.7 million people died from TB [1-3].

The main risk factors for developing active TB case are human immunodeficiency syndrome (HIV) infection, low socioeconomic status/poverty, alcoholism, homelessness, crowded living condition, diseases that weaken the immune system, migration from country with high number of cases, and health-care workers [4]. Tuberculosis non-adherence is the major challenge in $\mathrm{TB}$ treatment

\footnotetext{
*Correspondence: habtsew@ymail.com

Department of Medical Nursing, School of Nursing, College of Medicine and Health Sciences, University of Gondar, Gondar, Ethiopia
}

which leads multidrug as well as extended drug-resistant TB $[5,6]$. Combating non-adherence is the key and cornerstone of anti TB treatment. The prevalence of nonadherence to anti-tuberculosis treatment is 50\% India, 15.5\% Thailand, $24.7 \%$ and 24.5 South Ethiopia [7-10].

The main reasons for non-adherence in anti-tuberculosis treatment are drug side effects, forgetting to take medication, be away from home, missing date of appointment, lack of transportation cost, lack of social support, poor communication between patient and healthcare providers, and stock out of medicines [11-13]. Nonadherence to anti TB treatment results in increased length and severity of illness, death, disease transmission and drug resistance. It has great economic impact in terms of cost to patients as well as the health care system $[13,14]$.

Adherence to long course TB treatment is complex, dynamic phenomenon with wide range of factors impacting on treatment taking behaviors [15]. Even though there is wide coverage of DOTs program in Ethiopia, 
there is paucity of evidence on rate, reasons and associated factors of non-adherence on anti TB treatment particularly in the study area. Therefore the present study determines prevalence, reasons and associated factors of non-adherence of anti TB treatment among TB patients.

\section{Main text}

\section{Study design and setting}

Institutional based cross-sectional study design was conducted among TB patients from May to June 2017 at Gondar town health centers. Gondar town is found about 737-km away from Addis Ababa. In the town, there are one governmental specialized hospital, one private hospital and eight governmental health centers which serve for more than five million populations. Maraki, Polly, and Azezo health centers were selected. In these health centers, there were around 713 TB patients.

\section{Source population}

All TB patients who were on anti $\mathrm{TB}$ treatment in Gondar town health centers were considered as source population.

\section{Inclusion/exclusion criteria}

All TB patients who took anti TB medication at least for 1 month were included in the study, whereas TB patients who were seriously ill and or unable to hear and speak were excluded.

\section{Sample size and sampling procedure}

The sample size was determined using single population proportion formula $(\mathrm{n}=[(\mathrm{Z} \alpha / 2) 2 \times \mathrm{P}(1-\mathrm{P})] / \mathrm{D} 2)$ with the assumption of $95 \%$ level of confidence and 5\% marginal error. Prevalence of non-adherence to anti TB treatment was taken $24.5 \%$ [10]. Taking $10 \%$ nonresponse rate the required sample size was 314 . Using simple random sampling three health centers were selected. Proportional allocation method TB patients were taken from selected health centers (Maraki health center 88, Polly health center 110, and Azezo health center 116) then each study participant was selected using systematic random sampling. Sampling interval (K) was $\sim 3$ in each health center thus every three participants were interviewed based on their order of arrival.

\section{Data collection tools and procedures}

Data was collected by using pretested structured questionnaire adapted from different literatures [10-12]. The questionnaire has socio-demographic information, characteristics of tuberculoses and anti- tuberculoses treatment, reasons for interruption taking medications, knowledge and attitude towards tuberculosis and anti-TB treatment, patient-provider relationship, and behavioral factors. Possible reasons for interruption of taking medications were listed with additional open ended option. Questions about interruption of taking medications were asked while participants report missed medications. There were nine knowledge, seven attitude and eight patient provider relationship questions. The correct responses were coded 1 and the incorrect responses coded 0 then the correct answers were added then participants who scored mean and above of the questions were labeled good knowledge, favorable attitude, and good patient-provider relationship (Additional file 1). Internal consistency of the questionnaire found good (Cronbach's alpha 0.67$)$. The inter-rater reliability was Cohen's Kappa 0.65 . The sensitivity, specificity, and correct classification were $98.3 \%, 71.2 \%$ and $85.0 \%$ respectively. Non-adherence was assessed based on number of pills reported to have been actually taken 1 month prior to data collection period divided by number of prescribed pills multiplied by $100 \%$. Patients who missed $\geq 10 \%$ of the total prescribed dose were considered non-adherent. Data were collected by four trained BSc nurses through intervieweradministered and reviewing their medical records.

\section{Data quality control technique}

Pretest was conducted among 5\% of the sample size before actual data collection and some modification was done. The questionnaire was first prepared in English and translated to local language Amharic and back to English for its consistency. One day training was given for data collectors and supervision was conducted on daily basis throughout data collection.

\section{Operational definition}

Non-adherent

Patients who missed $\geq 10 \%$ of total prescribed dose were considered non-adherent $[10,16]$.

\section{Knowledgeable, favorable attitude, and good patient-provider relationship}

Those respondents who scored points at mean and above for the knowledge, attitude, and patient-provider relationship questions respectively.

\section{Alcohol intake}

History of alcohol intake since time of starting anti-TB treatment.

\section{Comorbidity}

Presence of any of chronic disease along with TB.

\section{Data processing and analysis}

Data were checked for its completeness, coded and entered into Epi info Version 7 and exported to SPSS 
version 20 for analysis. Descriptive statistics were generated including frequency, percent, mean median, and standard deviation (SD). Tables and bar graph were used to display the findings. Univariate logistic regression was used to identify factors associated with non-adherence to tuberculosis treatment. Variables at $\mathrm{P} \leq 0.2$ in bivariate analysis were taken into multivariate logistic regression model to control possible confounders. Crude odds ratio (COR) and adjusted odds ratio (AOR) with 95\% CI were calculated. Variables at P-value $<0.05$ in multivariate logistic regression model were considered statistically significant, and odds ratios with corresponding $95 \%$ confidence intervals were reported as the measures of the degrees of association.

\section{Results}

\section{Socio-demographic characteristics of participants}

Total of 314 participants were interviewed with $97.5 \%$ response rate. The mean age of participants was 35.94 $(\mathrm{SD} \pm 13.83)$ years. More than half, $166(54.2 \%)$, of participants, were males, 135 (44.1\%) single and 193 (63.0\%) were orthodox christians. Two-thirds 193 (63.0\%) were Amhara by ethnicity. majority, 256 (83.7\%), and a quarter, $75(24.5 \%)$, were urban dwellers and grade $9-12$ by education, respectively. One hundred forty-five $(47.4 \%)$ were had distance of $3-5 \mathrm{~km}$ from TB clinic and more than half $158(51.6 \%)$ had > 30 min traveling time (Table 1).

\section{The overall level of non-adherence to anti-TB therapy} In this study, the rate of non-adherence to anti-TB therapy was 65 (21.2\%) (95\% CI 17.2, 26.1). The rate is higher $(47.0 \%)$ among return after default treatment category and lower (19.1\%) among new category.

\section{Participants' reasons for interruption of taking anti-TB medications}

Participants were asked about reason of interruption of taking medications while they report missing any number of medications. Seventy participants were reported missed anti-TB medications. Most of participants report more than one reason for missing. Forgetting 40 (23.1\%), Being busy with other work 35 (20.2\%), and being out of home/town 24 (13.9\%) were the major reasons of participants for interruption of taking anti-TB medications (Fig. 1).

Factors associated with non-adherence to anti-TB therapy In this study; treatment phase, co-morbidity, knowledge, patient-provider relationship, and alcohol intake were significantly associated factors.

Participants who were in continuation phase of treatment were 2.27 times $(\mathrm{AOR}=2.27,95 \% \mathrm{CI}(1.54,5.94))$ more likely non-adhere to their anti-TB therapy than
Table 1 Socio-demographic characteristic of TB patients attending TB clinic in health centers at Gondar town, Northwest Ethiopia, 2017 ( $n=306)$

\begin{tabular}{|c|c|c|}
\hline Variable & Frequency (n) & Percent (\%) \\
\hline \multicolumn{3}{|l|}{ Sex } \\
\hline Male & 166 & 54.2 \\
\hline Female & 140 & 45.8 \\
\hline \multicolumn{3}{|l|}{ Age } \\
\hline $18-28$ & 75 & 24.5 \\
\hline $29-38$ & 61 & 19.9 \\
\hline $39-48$ & 83 & 27.2 \\
\hline$\geq 49$ & 87 & 28.4 \\
\hline \multicolumn{3}{|l|}{ Marital status } \\
\hline Single & 135 & 44.1 \\
\hline Married & 117 & 38.2 \\
\hline Divorced & 36 & 11.8 \\
\hline Widowed & 18 & 5.9 \\
\hline \multicolumn{3}{|l|}{ Religion } \\
\hline Orthodox & 193 & 63.0 \\
\hline Protestant & 58 & 19.0 \\
\hline Muslim & 55 & 18.0 \\
\hline \multicolumn{3}{|l|}{ Ethnicity } \\
\hline Amhara & 234 & 76.5 \\
\hline Tigrie & 40 & 13.0 \\
\hline Kimant & 32 & 10.5 \\
\hline \multicolumn{3}{|l|}{ Residence } \\
\hline Urban & 256 & 83.7 \\
\hline Rural & 50 & 16.3 \\
\hline \multicolumn{3}{|l|}{ Educational status } \\
\hline Unable to read and write & 51 & 16.7 \\
\hline Able to read and write & 65 & 21.2 \\
\hline Grade 1-8 & 49 & 16.0 \\
\hline Grade 9-12 & 75 & 24.5 \\
\hline Diploma & 27 & 8.8 \\
\hline Degree and above & 39 & 12.8 \\
\hline \multicolumn{3}{|l|}{ Occupational status } \\
\hline Government employee & 119 & 38.9 \\
\hline Merchant & 35 & 11.4 \\
\hline Farmer & 25 & 8.2 \\
\hline Housewife & 47 & 15.4 \\
\hline Student & 27 & 8.8 \\
\hline Daily laborer & 29 & 9.5 \\
\hline Unemployed & 24 & 7.8 \\
\hline \multicolumn{3}{|l|}{ Income (Ethiopian Birr) } \\
\hline$\leq 1000$ & 134 & 43.8 \\
\hline $1001-2000$ & 81 & 26.5 \\
\hline $2001-3000$ & 50 & 16.3 \\
\hline$>3000$ & 41 & 13.4 \\
\hline \multicolumn{3}{|c|}{ Distance from TB clinic (single trip) ( $\mathrm{km}$ ) } \\
\hline$<3$ & 70 & 22.9 \\
\hline $3-5$ & 145 & 47.4 \\
\hline$>5$ & 91 & 29.7 \\
\hline
\end{tabular}


Table 1 (continued)

\begin{tabular}{lcl}
\hline Variable & Frequency $(\mathbf{n})$ & Percent (\%) \\
\hline Type of transportation to the TB clinic & & \\
Walking/foot & 84 & 27.5 \\
Public transport & 222 & 72.5 \\
Traveling time (single trip) (min) & & \\
$\leq 30$ & 148 & 48.4 \\
$>30$ & 158 & 51.6 \\
Cost of traveling (single trip) ( $n=222)$ (Ethiopian Birr) & \\
$\leq 10$ Birr & 114 & 51.4 \\
$>10$ Birr & 108 & 48.6 \\
\hline
\end{tabular}

those in intensive phase. Participants with more than one co-morbidity were 6.22 (AOR $=6.22$; $95 \%$ CI $(2.21$, 17.48)) more likely to be non-adhere than participants with no or one co-morbidity. Furthermore, participants who had poor knowledge about TB and anti-TB therapy were 4.11 times $(\mathrm{AOR}=4.11 ; 95 \%$ CI $1.57,10.75)$ more likely to be non-adherent compared with participants with good knowledge. In addition, participants who had poor patient-provider relationship were 4.6 times $(\mathrm{AOR}=4.60,95 \% \mathrm{CI} 1.63,12.97)$ as likely be nonadherent as who had good patient-provider relationship. The odds of anti-TB non- adherence was found high among participants who were alcohol intake history $(\mathrm{AOR}=5.03 ; 95 \% \mathrm{CI} 1.54,16.40)$ (Table 2$)$.

\section{Discussion}

In this study, the rate of non-adherence to antiretroviral therapy was found 21 point two percent This is in-line with studies done at Arba Minch governmental health institutions [9], Dawouro-zone public healthcare facilities [10], and Mbarara Hospital, Uganda [17] which reported $24.7 \%, 24.5 \%$ and $25 \%$, respectively.

However, it is higher than studies done in North Gondar Zone- Northwest Ethiopia (10\% and 13.6\%) [16], Khartoum state, Sudan (14\%) [18], State of Parana (8.5\% \%) [19], Kosovo (14.5\%) [6], and Thailand (15.6\%) [8]. This difference might be due to differences in sociodemographic characteristic, sample size, study designs, settings and time difference.

This finding is lower than studies conducted in Mekele, Ethiopia (55.8\%) [20], E ward of Mumbai Municipal Corporation, India (50\%) [7], Schenzhen, China (33.74\%) [21]. The variation might be due to differences in study settings, study design, and socio-demographic characteristics. Study participants in Mekele were TB/HIV coinfected and those TB patients attending in hospital were included. The study in E ward of Mumbai Municipal Corporation was prospective cohort study and in Schenzhen, China all health facilities with TB treatment service were included.

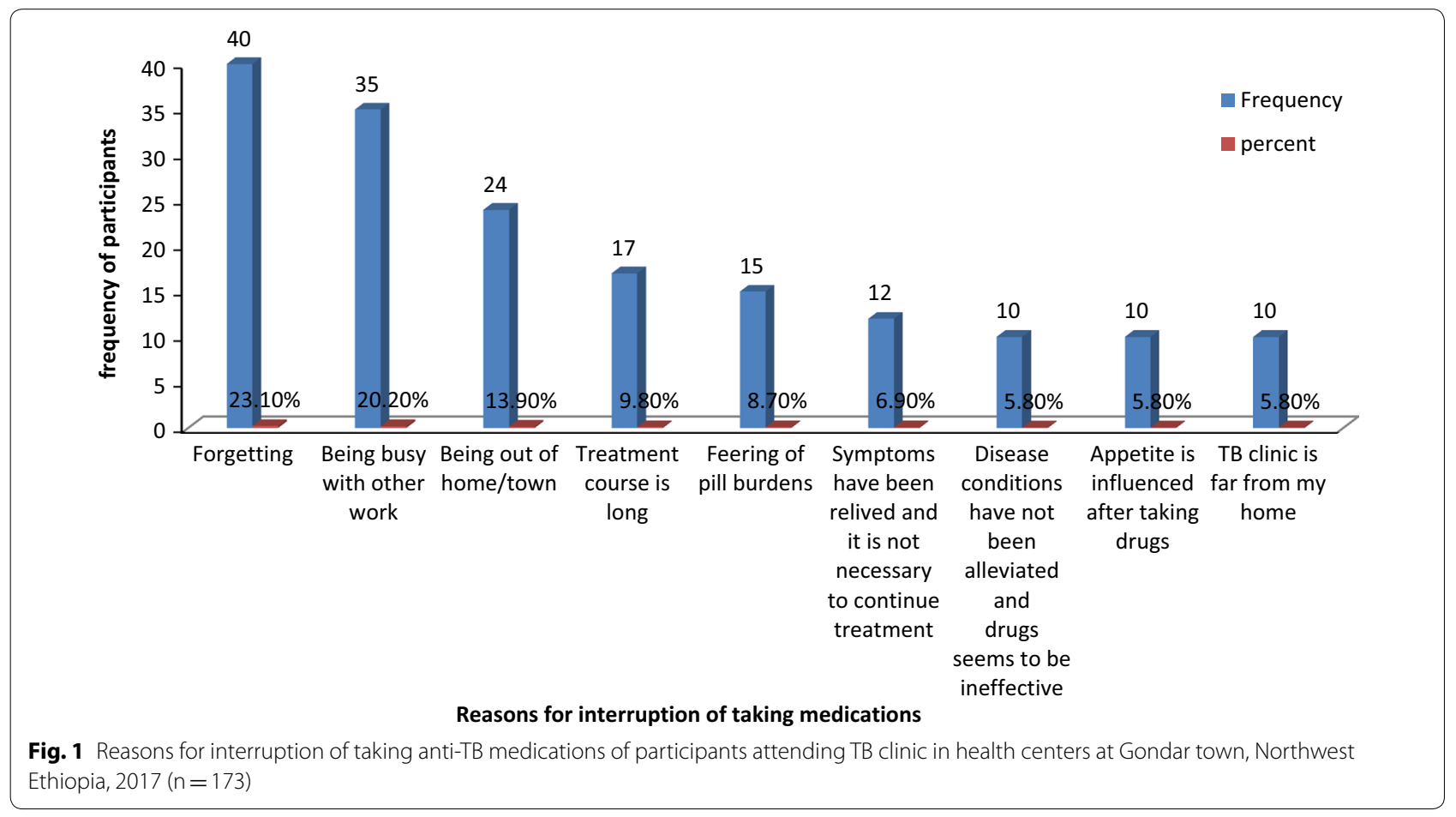


Table 2 Univariate and multivariate analysis for non-adherence to anti-TB therapy among TB patients attending TB clinic in health centers at Gondar town, Northwest Ethiopia, $2017(n=306)$

\begin{tabular}{|c|c|c|c|c|c|}
\hline \multirow[t]{2}{*}{ Variables } & \multicolumn{2}{|c|}{ Adherence status } & \multirow[t]{2}{*}{ COR $(95 \% \mathrm{Cl})$} & \multirow[t]{2}{*}{ AOR $(95 \% \mathrm{Cl})$} & \multirow[t]{2}{*}{ P-valu } \\
\hline & Adherent & Non adherent & & & \\
\hline \multicolumn{6}{|l|}{ Sex } \\
\hline Male & 133 & 33 & $0.84(0.48,1.45)$ & & \\
\hline Female & 108 & 32 & 1 & & \\
\hline \multicolumn{6}{|l|}{ Age } \\
\hline $18-28$ & 62 & 13 & 1 & 1 & \\
\hline $29-38$ & 48 & 13 & $1.29(0.55,3.04)$ & $3.22(0.68,15.17)$ & 0.139 \\
\hline $39-48$ & 70 & 13 & $0.89(0.38,2.05)$ & $0.83(0.18,3.88)$ & 0.808 \\
\hline$\geq 49$ & 61 & 26 & $2.03(0.96,4.32)$ & $2.44(0.53,9.41)$ & 0.272 \\
\hline \multicolumn{6}{|l|}{ Marital status } \\
\hline Single & 113 & 22 & $0.24(0.09,0.69)^{*}$ & $0.11(0.01,1.60)$ & 0.105 \\
\hline Married & 91 & 26 & $0.36(013,0.99)^{*}$ & $0.09(0.01,1.30)$ & 0.077 \\
\hline Divorced & 27 & 9 & $0.42(0.13,1.38)$ & $0.15(0.01,3.22)$ & 0.228 \\
\hline Widowed & 10 & 8 & 1 & 1 & \\
\hline \multicolumn{6}{|l|}{ Residence } \\
\hline Urban & 205 & 51 & $0.73(0.36,1.46)$ & & \\
\hline Rural & 36 & 14 & 1 & & \\
\hline \multicolumn{6}{|l|}{ Educational status } \\
\hline Unable to read and write & 41 & 18 & $0.59(0.16,2.12)$ & $1.28(0.21,7.62)$ & 0.789 \\
\hline Able to read and write & 45 & 20 & $2.62(0.96,7.12)$ & $1.12(0.20,6.37)$ & 0.899 \\
\hline Grade 1-8 & 44 & 5 & $1.24(0.40,3.80)$ & $0.41(0.06,3.01)$ & 0.381 \\
\hline Grade 9-12 & 65 & 10 & $1.01(0.35,2.93)$ & $2.12(0.34,13.11)$ & 0.420 \\
\hline Diploma & 22 & 5 & $1.10(0.30,4.07)$ & $1.48(0.19,11.66)$ & 0.710 \\
\hline Degree and above & 32 & 7 & 1 & 1 & \\
\hline \multicolumn{6}{|l|}{ Income (Ethiopian Birr) } \\
\hline$\leq 1000$ & 102 & 32 & 1 & 1 & \\
\hline $1001-2000$ & 60 & 21 & $1.12(0.59,2.12)$ & $1.65(0.50,5.51)$ & 0.414 \\
\hline $2001-3000$ & 43 & 7 & $0.52(0.21,1.27)$ & $0.47(0.09,2.38)$ & 0.365 \\
\hline$>3000$ & 36 & 5 & $0.44(0.16,1.22)$ & $0.12(0.01,1.30)$ & 0.081 \\
\hline \multicolumn{6}{|c|}{ Distance from TB clinic (single trip) (km) } \\
\hline$<3$ & 65 & 5 & 1 & 1 & \\
\hline $3-5$ & 121 & 24 & $2.58(0.94,7.08)$ & $1.83(0.38,8.78)$ & 0.450 \\
\hline$>5$ & 55 & 36 & $8.51\left(3.12,23.18^{*}\right.$ & $4.30(0.80,23.16)$ & 0.090 \\
\hline \multicolumn{6}{|c|}{ Type of transportation to the TB clinic } \\
\hline Walking/foot & 72 & 12 & 1 & 1 & \\
\hline Public transport & 169 & 53 & $1.88(0.95,3.73)$ & $1.80(0.54,6.01)$ & 0.338 \\
\hline \multicolumn{6}{|c|}{ Traveling time (single trip) (min) } \\
\hline$\leq 30$ & 131 & 17 & $0.30(0.16,0.55)^{*}$ & $0.48(0.11,2.11)$ & 0.330 \\
\hline$>30$ & 110 & 48 & 1 & 1 & \\
\hline \multicolumn{6}{|c|}{ Cost of traveling (single trip) $(n=222)$ (Ethiopian Birr) } \\
\hline$\leq 10$ Birr & 97 & 17 & $0.40(0.21,0.77)^{*}$ & $1.14(0.25,5.24)$ & 0.866 \\
\hline$>10$ Birr & 75 & 33 & 1 & 1 & \\
\hline \multicolumn{6}{|l|}{ Patients category } \\
\hline New & 190 & 45 & 1 & 1 & \\
\hline Treatment failure & 18 & 7 & $1.64(0.63,4.17)$ & $0.52(0.05,5.12)$ & 0.58 \\
\hline Relapse & 24 & 5 & $0.88(0.32,2.43)$ & $0.94(0.19,4.75)$ & 0.94 \\
\hline Return after default & 9 & 8 & $3.75(1.37,10.27)^{*}$ & $0.88(0.05,14.39)$ & 0.93 \\
\hline
\end{tabular}


Table 2 (continued)

\begin{tabular}{|c|c|c|c|c|c|}
\hline \multirow[t]{2}{*}{ Variables } & \multicolumn{2}{|c|}{ Adherence status } & \multirow[t]{2}{*}{ COR $(95 \% \mathrm{Cl})$} & \multirow[t]{2}{*}{ AOR $(95 \% \mathrm{Cl})$} & \multirow[t]{2}{*}{ P-value } \\
\hline & Adherent & Non adherent & & & \\
\hline \multicolumn{6}{|l|}{ Treatment phase } \\
\hline Intensive phase & 183 & 35 & 1 & 1 & 0.030 \\
\hline Continuation phase & 58 & 30 & $2.70(1.53,4.78)^{*}$ & $2.27(1.5,5.94)$ & \\
\hline \multicolumn{6}{|l|}{ HIV status } \\
\hline Seronegative & 153 & 52 & $2.30(1.19,4.46)^{*}$ & $1.97(0.41,9.39)$ & 0.651 \\
\hline Seropositive & 88 & 13 & 1 & 1 & \\
\hline \multicolumn{6}{|l|}{ TB status disclosure to the family } \\
\hline Yes & 192 & 45 & 1 & 1 & \\
\hline No & 49 & 20 & $1.74(0.94,3.22)$ & $1.47(0.31,6.90)$ & 0.626 \\
\hline \multicolumn{6}{|l|}{ Number of comorbidity? } \\
\hline$>1$ & 89 & 49 & $5.23(2.81,9.74)$ & $6.22(2.21,17.48)^{* *}$ & 0.001 \\
\hline No or 1 & 152 & 16 & 1 & 1 & \\
\hline \multicolumn{6}{|l|}{ Knowledge } \\
\hline Good knowledge & 156 & 20 & 1 & 1 & 0.004 \\
\hline Poor knowledge & 85 & 45 & $4.13(2.29,7.44)^{*}$ & $4.11(1.57,10.75)^{* *}$ & \\
\hline \multicolumn{6}{|l|}{ Patient-provider relationship } \\
\hline Good patient-provider relationship & 183 & 32 & 1 & 1 & 0.004 \\
\hline Poor patient-provider relationship & 58 & 33 & $3.25(1.84,5.75)^{*}$ & $4.60(1.63,12.97)^{* *}$ & \\
\hline \multicolumn{6}{|l|}{ Alcohol intake } \\
\hline Yes & 35 & 23 & $3.22(1.73,6.00)^{*}$ & $5.03(1.54,16.40)^{* *}$ & 0.007 \\
\hline No & 206 & 42 & 1 & 1 & \\
\hline
\end{tabular}

*Variables those were significant during univariate logistic analysis at $P$ value 0.05

**Variables that were found to have significant association during multivariate analysis at $\mathrm{P}$-value $<0.05$

In the current study participants in the continuation phase of treatment had significant association with nonadherence. Possible justification could be patients in continuation phase might have improved sign and symptoms of disease and expected as they are cured, thus they might be careless in taking medications. This finding is supported by studies in North Gondar Zone-Northwest Ethiopia, Kassala state, Sudan [22], Mbarara HospitalUganda. Number of co-morbidity had significant association with outcome variable. Participants who had more than one co-morbidities were had poor adherence to anti-TB therapy, like similar study reported in North Gondar Zone-Northwest Ethiopia, uMgmgundlovu health district.

Poor knowledge about tuberculosis and anti-TB therapy had significant association with non-adherence. This is similar to the results of studies in Dawouro-zone public healthcare facilities, E ward of Mumbai Municipal Corporation-India, Schenzhen-China. Poor patient-provider relationship also had significant association. This agreed to findings of studies in Sodo woreda, Southern Ethiopia [23]. Besides, alcohol intake had significant association with non-adherence. This is similar to the State of Parana, Mbarara, and Baringo, Kenya [24].
Forgetting, Being busy with other work, and being out of home/town were the major reasons for most participants for interruption of taking anti-TB medications. Different studies in North Gondar Zone, Alamata District, Mekele, and Baringo-Kenya, revealed as forgetting was the major reason for medication taking interruption/ non-adherence. Being out of home/town was supported by studies in North Gondar Zone and Alamata District.

The finding of this study gives evidence based information for Federal Minister of Health of Ethiopia, regional health office, zonal and district health offices and other stake holders and the information will be used to design TB reduction strategies and take action to further decrease the level of drug non-adherence on anti-TB treatments and improve the outcome of TB treatments.

\section{Conclusion}

This study revealed relatively high non-adherence rate of tuberculosis treatment. To decline the TB treatment non-adherence and to improve treatment outcome of TB-patients; health professionals, health programmers and other stakeholders should give emphasis to prevention of co-morbidities, improving knowledge through health education, providing strong counseling about drug 
adherence with more emphasis on continuation phase of treatment and about disadvantage of alcohol intake, and strengthening of patient-provider relationship.

\section{Limitations}

Non-adherence was assessed according to data actually taken during the previous 1 month. So, participants might be subjected to recall bias. Patients attending the Hospital and health Posts were not included. This might impose limitation on generalization of findings to all TB patients in the town. In addition, this study did not assess the frequency of missed medications.

\section{Additional file}

Additional file 1. Questionnaire. Questionnaire English Version. The objectives of this study is to assess Non-Adherence to Anti-tuberculosis Treatment, Reasons and associated factors among TB patients attending at Gondar town health centers, Northwest Ethiopia . The questionnaire has socio-demographic information, characteristics of tuberculoses and anti- tuberculoses treatment, reasons for interruption taking medications, knowledge and attitude towards tuberculosis and anti-TB treatment, patient-provider relationship, and behavioral factors.

\section{Abbreviations}

AOR: adjusted odds ratio; Cl: confidence interval; COR: crude odds ratio; DOTs: directly observed therapies; HIV: human immune deficiency virus; SD: standard deviation; SPSS: statistical package for social sciences; TB: tuberculosis; WHO: World Health Organization.

\section{Authors' contributions}

HSM wrote the proposal, participated in data collection, analyzed the data and drafted the manuscript. AWA approved the proposal with revisions, participated in data collection, data analysis and revised subsequent drafts of the manuscript. Both authors read and approved the final manuscript.

\section{Acknowledgements}

Authors would like to express our gratitude to the University of Gondar College of Medicine and Health Science School of Nursing Research and Ethical Review committee for the approval of the ethical clearance. The authors would like to thank data collectors and supervisors for their commitment and the study participants for their valuable information.

\section{Competing interests}

The authors declare that they have no competing interests.

\section{Availability of data and materials}

The raw data would not be provided for the reason of protecting patients' confidentiality. But, the summary data are available in the main document.

\section{Consent to publish}

Not applicable.

\section{Ethics approval and consent to participate}

The study was approved by University of Gondar College of Medicine and Health Sciences School of nursing Research and Ethical Review Committee with the Reference Number C/N/035/09/09. A permission and supportive letter were obtained from the head of each health centers. Each study participant was informed about the purpose, method, expected benefit, and risk of the study. They were also informed about their full right not to participate or withdraw from the study at any time, and deciding not to participate had no impact on their services. Written informed consent was obtained from study participants and anonymity was employed to maintained confidentiality.

\section{Funding}

The authors received no specific funding for this work.

\section{Publisher's Note}

Springer Nature remains neutral with regard to jurisdictional claims in published maps and institutional affiliations.

Received: 2 July 2018 Accepted: 25 September 2018

Published online: 01 October 2018

\section{References}

1. Organization WH. Global tuberculosis report 2017. Geneva: World Health Organization; 2017

2. Organization WH. Multi drug resistant tuberculosis (MDR-TB) Uptodate WHO Global tuberculosis program; 2017.

3. Organization WH. Global strategy and targets for tuberculosis prevention, care and control after 2015, the end TB strategy. Geneva: World Health Organization; 2015.

4. Schiffman G. Tuberculosis, Test, causes, treatmentand Prognosis. eMedicineHealth. https://www.emedicinehealth.com/tuberculosis/artic le_em.htm.

5. Jain A, Dixit P. Multidrug resistant to extensively drug resistant tuberculosis: What is next? J Biosci. 2008;33:605-16.

6. Krasniqi S, Jakupi A, Daci A, Tigani B, Jupolli-Krasniqi N, Pira M, Zhjeqi V, Neziri B. Treatment adherence of patients in Kosovo. Hindawi Tuberculosis Research and Treatment, 2017;2017. https://doi. org/10.1155/2017/4850324

7. Kulkarni PYAS, Mankeshwar RM, Bhawalkar JS, Banerjee A, Kulkarni AD. Non adherence of new pulmonary tuberculosis patients to anti tuberculosis treatment. Ann Med Health Sci Res. 2013;3(1):67-74.

8. Peltzer K, Pengpid S. Predictors of non-adherence to anti-tuberculosis medication in tuberculosis patients in Thailand. J Hum Ecol. 2017;52(1,2):26-31.

9. Gube AA, Mengesha A, Debalkie M, Zeynu A, Seid K, Shimelis F, Bisete K, Gebremeskel K. Assessment of anti-TB drug nonadherence and associated factors among TB patients attending TB clinics in Arba Minch Governmental Health Institutions, Southern Ethiopia. Hidawi. 2018;2018.

10. Woimo TT, Yimer WK, Bati T, Gesesew HA. The prevalence and factors associated for anti-tuberculosis treatment non-adherence among pulmonary tuberculosis patients in public health care facilities in South Ethiopia: a cross-sectional study. BMC Public Health. 2017;17:269.

11. Tesfahuneygn $G$, Medhin G, Legesse M. Adherence to anti-tuberculosis treatment and treatment outcomes among tuberculosis patients in Alamata District, northeast Ethiopia. BMC Res Notes. 2015;8:503. https:// doi.org/10.1186/s13104-015-1452-x.

12. Habteyes Hailu T, Shojaeizadeh D, Garmaroudi G. Tuberculosis treatment non-adherence and lost to follow up among TB patients with or without HIV in developing countries: a systematic review. Iran J Public Health. 2015:44:1-11.

13. SIAPS U. The economic cost of non-adherence to TB medicines resulting from stock-outs and loss to follow-up in Kenya. 2017.

14. SIASPS U. Economic cost of non-adherence to tb medicines resulting from stock-outs and loss to follow-up in the Philippines. 2016.

15. Munro SA, Lewin SA, Smith HJ, Engel ME, Fretheim A, Volmink J. Patient adherence to tuberculosis treatment: a systematic review of qualitative research. PLoS Med. 2007:4:e238.

16. Adane AA, Alene KA, Koye DN, Zeleke BM. Non-adherence to antituberculosis treatment and determinant factors among patients with tuberculosis in northwest Ethiopia. PLoS ONE. 2013;8(11):e78791. https:// doi.org/10.1371/journal.pone.0078791.

17. Monica G, Amuha PK, Kitutu FE, Odoi-Adome R, Kalyango JN. Non-adherence to anti-TB drugs among TB/HIV co-infected patients in Mbarara Hospital Uganda: prevalence and associated factors. Afr Health Sci. 2009;9(1):S8-15. 
18. Ali $\mathrm{AO}$, Prins $\mathrm{MH}$. Patient non adherence to tuberculosis treatment in Sudan: socio demographic factors influencing non adherence to tuberculosis therapy in Khartoum State. Pan Afr Med J. 2016:25:80.

19. Furlan MCR, Oliveira SP, Marcon SS. Factors associated with nonadherence of tuberculosis treatment in the state of Paraná. Acta Paul Enferm. 2012;25(1):108-14.

20. Eticha T, Kassa E. Non-adherence to anti-TB drugs and its predictors among TB/HIV co-infected patients in Mekelle, Ethiopia. J Bioanal Biomed. 2014:6:061-4. https://doi.org/10.4172/1948-593X.1000113.

21. Tang Y, Zhao M, Wang Y, Gong Y, Yin X, Zhao A, Zheng J, Liu Z, Jian X, Wang W, Wu C, Lu Z. Non-adherence to anti-tuberculosis treatment among internal migrants with pulmonary tuberculosis in Shenzhen, China: a cross-sectional study. BMC Public Health. 2015;15:474.

22. Mohammed El-Muttalut MK. Factors contributing to non-compliance with treatment among tuberculosis patients-Kassala State-Sudan-2016. Int J Public Health Epidemiol. 2017;6(3):332-8.

23. Cherinet Gugssa Boru TS, Bilal Al. Factors contributing to non adherence with treatment among TB patients in Sodo Woreda Guragie zone, southern Ethiopia, a qualitative study. J Infect Public Health. 2017;10:527-33.

24. Obwoge RO, Sang RA, Wakube A. Factors associated to non-adherence in tuberculosis treatment, Baringo County, Kenya. Int J Sci Res Innov Technol. 2016;3(2):85
Ready to submit your research? Choose BMC and benefit from:

- fast, convenient online submission

- thorough peer review by experienced researchers in your field

- rapid publication on acceptance

- support for research data, including large and complex data types

- gold Open Access which fosters wider collaboration and increased citations

- maximum visibility for your research: over $100 \mathrm{M}$ website views per year

At BMC, research is always in progress.

Learn more biomedcentral.com/submissions 